\title{
The Effects of Binder on the Physical Characteristic of Squeezed Rhizome of Kaempferia galanga L Lozenges
}

\author{
Uswatun Chasanah", Fairuzly Yulian, Rizki Yulianty, Adzan Irianto and Achmad \\ Radjaram \\ Department of Pharmacy, Faculty of Health Science, University of Muhammadiyah Malang, \\ Indonesia \\ Jalan Bendungan Sutami 188A, Kota Malang, Jawa Timur 65145 \\ *Corresponding author: uswatunchasa97@gmail.com
}

\begin{abstract}
Background: The lozenge is one of the drugs to overcome a sore throat. This contained an active ingredient can be either a synthetic or herbal materials. Kaempferia galanga L is a medicinal plant that able to relieve cough and sore throat. So, its potential made be lozenges. Lozenges are compressed tablets which it must be using the binders on formulation. Objectives: This study was to investigate the effect of the binder on physical characteristic of squeezing rhizome of Kaempferia galanga lozenges using mannitol base. Evaluation was conducted using different kinds of binders (i.e., gelatin, hydroxypropylmethylcellulose (HPMC) $1290 \mathrm{cps}$ and polyvinylpyrrolidone (PVP) K30 at 1\%,2\%, and 3\% concentrations. Methods: The squeezed rhizome of Kaempheria galanga L was dried using mannitol. The lozenges were prepared by a wet granulation method and compressed by a hydraulic press at 2-ton pressures. Lozenges had been evaluated, including hardness, fragility, and dissolves time of lozenges. Conclusion: Lozenges that contained Gelatine and PVP K3O in the concentration of $2 \%$ and $3 \%$, both of them were as well at the range. While the lozenges that containd HPMC 1290 cps provides good results at the concentration of 3\%. All parameters are dependent on the type, quality and concentration of a binder.
\end{abstract}

Keywords: Kaempferia galanga; Gelatin; HPMC 19203 cps; PVP K-30; wet granulation; lozenges.

\section{INTRODUCTION}

Lozenge is one of the drug used to overcome the sore throat. The active ingredients of lozenge formulation can be either synthetic or herbal materials (Mendes \& Bhargava 2006). One of the herbal ingredients that can be used as an active ingredient of lozenges is Kaempferia galanga L because it contained essential oil especially ethyl trans-pmethoxycinnamate that has antibacterial activity (Wong, Ong, \& Lim 1992; Supinya et al. 2005).

Lozenges are compressed tablets formulated, without a disintegrate that contain one or more medicaments, usually in a flavored, sweetened base, and intended to dissolve or disintegrate slowly in the mouth to provide drug delivery locally to the mouth, tongue and throat. They can be prepared by molding (gelatin and/or fused sucrose and sorbitol base) or by compression of sugar-based tablets. Lozenge tablets are generally formulated as relatively large-diameter ( $>12.5 \mathrm{~mm}$ ), flat-faced (beveled edge), heavy $(>700 \mathrm{mg}$ ) tablets more hardness (> $15 \mathrm{~kg}$ ) (Mendes \& Bhargava 2006). 
Wet granulation is most commonly used method for the manufacturing of tablets. The advantages of wet granulation method is reduced segregation of formulation components during storage and processing. Leading to reduced intra and inter batch variability. In wet granulation process, binders promote size enlargement to produce granules and thus improve flow ability of the blend during the manufacturing process. The clasification of binders are sugar (i.e., sukrosa, mannitol, liquid glucose), natural binders (i.e., acasia, tragacanth, gelatin, starch paste, pregelatinazed starch, alginic acid, cellulose), and synthetic/semi-synthetic polymers (i.e., Methyl Cellulose, Ethyl Cellulose, Hydroxy Propyl Methyl Cellulose (HPMC), Sodium Carboxy Methyl Cellulose, Polyvinyl Pyrrolidone (PVP), Polyethylene Glycol (PEG), Polyvinyl Alcohols, Polymethacrylates) (Fred J. Bandelin 1989, Karthik Varma 2016)

Therefore, this study has been done to investigate the effects of different binders on the physical characteristic of squeezed Kaempferia galanga rhizome lozenges prepared by the wet granulation method. To achieve this research, studies were conducted using three different binders with different concentration, namely Gelatin, HPMC 2910 3cps, PVP K30 at $1 \%, 2 \%$ and $3 \%$. Effects of binders were assessed by testing hardness, friability and dissolve time.

\section{METHOD}

\section{Materials}

Kaempferia galanga L rhizome as a drug. Mannitol as the filler. Polyvinylpyrrolidone (PVP) K 30, hydroxypropyl methylcellulose (HP MC) 2910 3cPs and gelatine were used as binders. Magnesium stearate was used as a lubricant. Aspartame was a sweating agent.

\section{Preparation of drying squeezed of Kaempferia galanga in mannitol}

The freshness of Kaempferia galanga Rhizoma was blended, then squeezed. The squeezed were evaporated in water bath until the volume reduced about a half and then added the mannitol. It was dried at $40-50^{\circ} \mathrm{C}$ for 24 hours.

\section{Preparation of granules}

Batch of Kaempferia galanga lozenges formulations containing drying squeezed of Kaempferia galanga in mannitol + Gelatine or HPMC 2910 3cPs or PVP K30 + aspartame + magnesium stearate (Table 1).

Table 1 The Formulation of Kaempferia galanga $L$ rhizome lozenges with $1 \%, 2 \%$ and $3 \%$ of the binders (w/w)

\begin{tabular}{|c|c|c|c|c|c|c|c|c|c|c|}
\hline \multirow{2}{*}{ Materials } & \multicolumn{4}{|c|}{ Gelatine } & \multicolumn{3}{|c|}{ HPMC $19203 \mathrm{cps}$} & \multicolumn{3}{|c|}{ PVP K30 } \\
\hline & $0 \%$ & $1 \%$ & $2 \%$ & $3 \%$ & $1 \%$ & $2 \%$ & $3 \%$ & $1 \%$ & $2 \%$ & $3 \%$ \\
\hline $\begin{array}{l}\text { Drying squeezed } \\
\text { rhizome of } \\
\text { Kaempferia galanga } \\
\text { in mannitol (mg) }\end{array}$ & 1980 & 1960 & 1940 & 1920 & 1960 & 1940 & 1960 & 1960 & 1940 & 1920 \\
\hline Gelatine (mg) & - & 20 & 40 & 60 & - & - & - & - & - & - \\
\hline HP MC $2910(\mathrm{mg})$ & - & - & - & - & 20 & 40 & 60 & - & - & - \\
\hline PVP K30 (mg) & - & - & - & - & - & - & - & 20 & 40 & 60 \\
\hline Aspartame (mg) & 10 & 10 & 10 & 10 & 10 & 10 & 10 & 10 & 10 & 10 \\
\hline $\begin{array}{l}\text { Magnesium stearate } \\
(\mathrm{mg})\end{array}$ & 10 & 10 & 10 & 10 & 10 & 10 & 10 & 10 & 10 & 10 \\
\hline Weight of tablet (mg) & 2000 & 2000 & 2000 & 2000 & 2000 & 2000 & 2000 & 2000 & 2000 & 2000 \\
\hline
\end{tabular}


The drying of the squeeze of Kaempferia galanga rhizome in mannitol was mixing with binder solution and aspartame to got consistancy of wetness and then kneaded well. The wet mass was screened through sieve \#12 $(710 \mathrm{~mm})$ to making small granules. The granules were dried at $50^{\circ} \mathrm{C}$ overnight in an oven and screened through a sieve \#16 $(100 \mu \mathrm{m})$. The granules were stored in airtight containers.

\section{Evaluation of the granules}

Determination of moisture content

The moisture content of each batch of the granules was determined on a wet-weight basis on an Ohaus moisture balance (Ohaus Scale Corporation, New Jersey, USA). Quantities (2g) of each sample was uniformly spread on the sample pan and then the heating cycle was started. The percentage moisture content which is the percent weight loss from the sample by heating was displayed on the equipment. The instrument was allowed to cool between tests.

\section{Angle of repose}

The static angle of repose was determined using the fixed base cone method. A $100 \mathrm{~g}$ quantity of the sample was transferred into an open-ended cylinder placed on a static base cone on a horizontal surface. The cylinder was gradually withdrawn vertically and the sample formed a cone-shaped heap. The height of the sample (h) was determined using a cathetometer; the radius ( $r$ ) was gotten by dividing the fixed diameter by two. Angle of repose $(\Theta)$ for each sample was gotten using the equation;

$$
\Theta=\tan -1 \mathrm{~h} / \mathrm{r}
$$

\section{Granule size distribution}

The size distribution of each granule formulation was determined by sieve analysis (British Standard 1460). A stack of sieves of the following sizes: 40 mesh $(425 \mu \mathrm{m}) 60$ mesh $(250$ $\mu \mathrm{m}), 80$ mesh $(180 \mu \mathrm{m}), 120$ mesh $(125 \mu \mathrm{m})$ and the receiver, was arranged in descending order of aperture size with the receiver at the bottom. One hundred gram of granules was put on the uppermost sieve, firmly covered and the stack of sieves was shaken for 10minutes on a sieve shaker (Pascal Engineering, Essex, England). The quantity of granules retained on each sieve was weighed and the percentage of fine, was calculated.

\section{Preparation of lozenges}

Quantities (2000mg) of the powder and granule formulations of lozenges were compressed for $1 \mathrm{~min}$ into tablets with pre-determined loads, using hydraulic hand, using $20 \mathrm{~mm}$ die and flat faced punches. After compression, lozenges was stored in airtight containers for 24 hours to allow for elastic recovery and hardening and to prevent falsely low yield value.

\section{Evaluation of Lozenges}

\section{Hardness test}

Tablet hardness tester was used to measure the hardness. Five lozenges tablets were selected randomly from each formulation for tested. Lozenge was placed between the spindle and anvil of the tester and the calibrated length adjusted to zero. The knob was then screwed to apply a diametric compression force on the tablet and the position on the calibrated length at which the tablet broke was recorded in kg units. A mean hardness was calculated for each batch and thus their standard deviations and coefficient of variations were calculated. Term of hardness lozenge is $10 \mathrm{~kg}$ to $20 \mathrm{~kg}$ (Parrot 1970). 


\section{Friability test}

The friability testing of lozenges made using friabilator tester. Performed with 10 lozenges selected randomly. The lozenges Dusted carefully from the prior testing Lozenges weighed accurately, and place in the drum. The drum is rotated at $25 \mathrm{rpm}$ for 100 rotations and remove the lozenges. Then lozenges are dusted with a brush, and then accurately weighed. The friability expressed as a weight loss percentage (USP 29 2006).

\section{Dissolve time}

Testing time dissolving tablet using a Disintegration Tester. This device consists of a basket containing six plastic cylinder that opened on top and base covered with a sieve size of 10 mesh. The number of tablets used to test amounted to 6 . The basket put in a beaker containing water with a temperature of $37^{\circ} \mathrm{C} \pm 0,5^{\circ} \mathrm{C}$, as the media. Each tablet is inserted into each cylinder, then raised and lower the basket with a fixed frequency between 28-32 times per minute until the tablets disintegrate. Time-dissolving tablet is calculated when the tablets on the basket starts lowered into the media tablet runs until dissolved. The test was repeated 3 times and the average was determined (USP 29 2006).

\section{RESULT AND DISCUSSION}

The squeeze was obtained from $1 \mathrm{~kg}$ of fresh Kaempferia galanga L rhizome is 300 $\mathrm{ml}$, the juice is subsequently dried with $265 \mathrm{~g}$ of mannitol. The obtained of the squeeze rhizome of Kaempferia galanga in mannitol powder was $280 \mathrm{~g}$.

The result of evaluating the granules of Squeezed Rhizome of Kaempferia galanga L, namely the values of percentage moisture content, angle of repose, and percentage of fine are presented in Table 2.

Moisture content. The moisture content of all batch granules with different types and quantities of binders are within the specified range (1-2\%). The moisture content in granules is an important factor in granule quality, chemical stability of the material, and the possibility of microbial contamination. The dried granules still contain certain moisture. The moisture content that is too low increases the likelihood of capping while the moisture content is too high increases the likelihood of picking on the preparation (Aulton, M.E. 2002).

Table 2 Properties of formulations containing different types and quantities of binders

\begin{tabular}{lllll}
\hline \multirow{2}{*}{ Parameters } & Binder & \multicolumn{2}{l}{ Type of Binder } & \\
\cline { 3 - 5 } Conc. & Gelatin & HPMC 1920 & PVP K330 \\
\hline Moisture content $(\%)$ & $0 \%$ & $1,47 \pm 0,13$ & $1,31 \pm 0,35$ & $1,47 \pm 0,13$ \\
& $1 \%$ & $1,35 \pm 0,10$ & $1,19 \pm 0,03$ & $1,35 \pm 0,10$ \\
Angle of repose $\left(^{\circ}\right)$ & $2 \%$ & $1,14 \pm 0,04$ & $1,26 \pm 0,11$ & $1,14 \pm 0,04$ \\
& $3 \%$ & $1,47 \pm 0,23$ & $1,37 \pm 0,23$ & $1,47 \pm 0,23$ \\
& $0 \%$ & $35,57 \pm 1,97$ & $36,23 \pm 0,08$ & $35,57 \pm 1,97$ \\
Fines $(\%)$ & $1 \%$ & $31,61 \pm 0,42$ & $36,27 \pm 1,05$ & $31,61 \pm 0,42$ \\
& $2 \%$ & $33,85 \pm 0,29$ & $35,76 \pm 0,99$ & $33,85 \pm 0,29$ \\
& $3 \%$ & $34,78 \pm 0,82$ & $28,89 \pm 0,35$ & $34,78 \pm 0,82$ \\
& $0 \%$ & $1,30 \pm 0,20$ & $1,30 \pm 0,20$ & $1,30 \pm 0,20$ \\
& $1 \%$ & $0,85 \pm 0,17$ & $0,59 \pm 0,10$ & $0,85 \pm 0,17$ \\
& $2 \%$ & $0,43 \pm 0,04$ & $0,42 \pm 0,04$ & $0,43 \pm 0,04$ \\
& $3 \%$ & $0,66 \pm 0,02$ & $0,30 \pm 0,01$ & $0,66 \pm 0,02$ \\
\hline
\end{tabular}




\section{Angle of repose}

For result of angle of repose measurement, all batch formulation are within the range of $30^{\circ}-40^{\circ}$, this means that the flow rate of the granules are good (Carl RL 1965, USP 29) The magnitude of the angle of repose is influenced by the shape, size and moisture of granules The angle of repose test describes the flow properties of the powder during the process of making the tablet. The magnitude of the angle of repose is influenced by the tensile force and friction between the particles, if the tensile force and friction force are weak, the granules will be faster and easier to flow (Fonner, et al, 1981, USP 29). The more conical the resulting, the smaller the angle the slope and the better the flow properties of the powder.

\section{Percentage of fine}

Particle size can affect the average weight, weight variation, crushed time of the tablet, flow rate and kinetics of drying speed in wet granulation. A good granules have a number of fines $<20 \%$. If the number of fines a bit then it will reduce the angle of repose, otherwise if the number of fines a large, it will increase the angle of repose. In addition, fines affect the flow properties and uniformity of tablet weight. Resulting measurement of fines in all formulation showed that 2 all batch formulation have fine less than $20 \%$, thus distribution of particle size for all batch are good.

\section{Effects of the binder on the tablet hardness}

Tablet hardness of all batch was shown in Table 3. It appears that with the increasing concentration of the binder, the hardness of the tablet is also increasing. Increasing the amount of binder added to a compound resulted in a gradual decrease in tablet porosity as more of the interparticulate voids were filled with binder. That tablets hardness for all formulations used binder at $2 \%$ and $3 \%$ concentrations were more than $10 \mathrm{~kg}$ and less than $15 \mathrm{~kg}$, except which used HPMC $19203 \mathrm{cps}$ at 2\% concentration. This indicated that hardness varied with the binder type. Polymeric binder, PVP, and natural binder, gelatine showed high values and starch binder, otherwise HP MC 1920 3cps gave the lowest value for hardness.

Table 3 The Quality Physical of Squeezed Rhizome of Kaempferia galanga Lozenges

\begin{tabular}{|c|c|c|c|c|}
\hline \multirow{2}{*}{ Parameters } & \multirow{2}{*}{$\begin{array}{l}\text { Binder } \\
\text { Conc. }\end{array}$} & \multicolumn{3}{|c|}{ Type of Binder } \\
\hline & & Gelatin & HPMC 1920 & PVP K330 \\
\hline \multirow[t]{4}{*}{ The Hardness } & $0 \%$ & $6.20 \pm 0.16$ & $6.20 \pm 0.16$ & $6.20 \pm 0.16$ \\
\hline & $1 \%$ & $8.25 \pm 0.26$ & $7.58 \pm 0.57$ & $8.33 \pm 0.21$ \\
\hline & $2 \%$ & $10.25 \pm 0.20$ & $9.33 \pm 0.35$ & $10.40 \pm 0.32$ \\
\hline & $3 \%$ & $12.20 \pm 0.16$ & $11.18 \pm 0.33$ & $12.20 \pm 0.20$ \\
\hline \multirow[t]{4}{*}{ The Friabilitas } & $0 \%$ & $1.11 \pm 0.12$ & $1.11 \pm 0.12$ & $1.11 \pm 0.12$ \\
\hline & $1 \%$ & $0.28 \pm 0.05$ & $0.97 \pm 0.02$ & $0.33 \pm 0.11$ \\
\hline & $2 \%$ & $0.28 \pm 0.03$ & $0.79 \pm 0.05$ & $0.26 \pm 0.05$ \\
\hline & $3 \%$ & $0.26 \pm 0,20$ & $0.33 \pm 0.06$ & $0.20 \pm 0.05$ \\
\hline \multirow[t]{4}{*}{ The Dissolve Time } & $0 \%$ & $6.17 \pm 0.29$ & $6.17 \pm 0.29$ & $6.17 \pm 0.29$ \\
\hline & $1 \%$ & $7.00 \pm 0.00$ & $8.17 \pm 0.29$ & $6.67 \pm 0.29$ \\
\hline & $2 \%$ & $7.67 \pm 0.29$ & $8.83 \pm 0.29$ & $7.17 \pm 0.29$ \\
\hline & $3 \%$ & $8.50 \pm 0.50$ & $9.83 \pm 0.29$ & $8.67 \pm 0.29$ \\
\hline
\end{tabular}


Hardness of tablets depends on the degree of binding which relies on the amount of the binder and the compression force. The higher hardness of the tablet with the binder can be related to its film formation ability and its cohesive strength to make solid bonds between particles. As a result, the binder is forced into the inter particulate spaces resulting more solid bond between granules (Rowe 1990)

\section{Effects of the binder on the friability}

Friability corresponding to each binder (table 2), it was observed that tablets friability for all formulation was less than $1 \%$, indicating the intergranular forces between the granules is higher (USP 29 2006), it means that all lozenges pass the friability test. The lozenges used gelatin showed the low percentage weight loss at $1 \%, 2 \%$ and $3 \%$, as same as showed the lozenges used PVP, which have percentage weight slightly different with lozenges used gelatine. Otherwise, lozenges used HP MC 1290 3cps have percentage weight less more than the others. This proves that tablets that have high hardness will have low fragility.

\section{Effects of the binder on the dissolve time}

The dissolve times obtained for all formulations were shown at Table 2. The dissolve time for all formulation were more than 5 minutes and less than 10 minutes, as shown in Fig.1, this indicates the all lozenges pass to dissolve time test (USP 29 2006). Gelatin softens and dissolves in water, HP MC 1290 3cps swelling and dissolve in water, and PVP K30 dissolves in water, too (Rowe, Sheskey, \& Quinn 2009). Lack of hydrophobic material on formulation of lozenges makes it easy to dissolve.

\section{CONCLUSION}

In conclusion, I would like to mention that the investigated on the effects of the binder to the physicochemical properties of the lozenges has established the fact that the physicochemical properties, type, quality and concentration of binder itself are the main factors that affect the ultimate quality of the tablet. Results proved that the binders, PVP and gelatine solution, are good binders for preparation of the squeeze of Kaempferia galanga rhizome lozenges at 2\% and 3\% concentration. While HP MC $12903 \mathrm{cps}$ at concentration of $3 \%$.

\section{REFERENCES}

Aulton, M.E., Summer, M., 2002. Tablet and Compaction in : Pharmacutic The Science of Dosage Forms Design. $2^{\text {nd }}$ Edition. Churchill Livingstone. Philadelphia

Carl RL. 1965. USP 29/NF 24. Powder Flow http://www.pharmacopeia.cn/v29240/usp29 nf24s0_c1174.html

Fonner, D.E., Anderson, N.R., Banker, G.S., 1981, Granulation and tablet characteristic, in: Pharmaceutical dosage forms: Tablet volume 2. Edited by Lieberman, H., \& Lachman, L., New York: Marcel Dekker; p. 223-6.

Fred J. Bandelin . 1989. Compressed Tablets by Wet Granulation in: Pharmaceutical dosage forms- -tablets, edited by Herbert A. Lieberman, Leon Lachman, Joseph B. Schwartz. -- 2nd ed., New York and Basel: Marcel Dekker, Inc., p. 131-90.

K.C. Wong, K.S. Ong, and C.L.Lim. 1992. "Composition of the essential oil of rhizomes of kaempferia galanga L.," Flavor and Fragrance Journal. (7): 263-266.

Karthik Varma V.2016. Excipients used in the Formulation of Tablets, Journal of Chemistry. Mendes, RW and Bhargava H. 2006. Lozenges. In: Swarbick J, editor. Encyclopedia of Pharmaceutical Technology. 3rd ed. North California, USA: Informa Healthcare Inc.; pp. 990, 2231-2235. 
Parrot, E.L. 1970. Pharmaceutical Technology, United States of America: Burgess Publishing Company. R. C. Rowe. Feb. 1990. "Correlation between predicted binder spreading coefficients and measured granule and tablet properties in the granulation of paracetamol" Int. J. Pharmaceutics, vol 58, pp-209-213,.

Parrot, E.L., 1971. Pharmaceutical Technology, Fundamental Pharmaceutics, $3^{\text {rd }}$ ed, Mineapolis USA: Burges Publishing Company.

R C Rowe, PJ Sheskey, and M E Quinn. 2009. Handbook of Pharmaceutical Excipients $26^{\text {th }}$ ed. Pharmaceutical Press and American Pharmacists: 278, 326, 611.

Supinya Tewtrakul, Supreeya Yuenyongsawad, Sopa Kummee and Latthya Atsawajaruwan. 2005. "Chemical components and biological activities of volatile oil of Kaempferia galanga Linn.," Songklanakarin J. Sci. Technol., 27(2): 503-507

USP 29/NF 24. Tablet Friability.

USP 29/NF 24.2006. United state pharmacopoeial convention, Toranto, Asian Edition; pp. 701

USP/NF 24. Disintegration 